\title{
A MENSURAÇÃO DA MIGRAÇÃO DE DATA-FIXA NO BRASIL COM BASE NOS CENSOS DEMOGRÁFICOS: DIFICULDADES E INCONSISTÊNCIAS
}

Ricardo Alexandrino Garcia ${ }^{1}$

\begin{abstract}
Resumo: nos estudos populacionais no Brasil, verifica-se que uma crescente atenção dada à mensuração dos fluxos migratórios. Nos censos de 1960 e de 1970 as questões sobre migração foram direcionadas apenas aos não-naturais dos municípios e estes quesitos dizem respeito ao tempo de residência sem interrupção na UF e no município, lugar de procedência (UF ou país estrangeiro) e situação do domicílio (urbano ou rural). No Censo de 1980, houve avanços importantes, porém, foi no Censo de 1991, que houve a introdução da informação de "data fixa", obtida por meio do quesito que indagava aos moradores a UF e o nome do município ou país em que residia em exatos cinco anos atrás. Nos últimos três Censos, no entanto, o processamento dessa informação apresentou peculiaridades cuja discussão é o objeto deste artigo. Além de explicitar a distribuição espacial desses movimentos nas últimas décadas, a principal conclusão deste artigo sugere que uma cautela a mais deva ser dada à mensuração da migração de data-fixas no Censo Demográfico de 2010.
\end{abstract}

Palavras-chave: migração de data-fixa; microdados; Censos Demográficos; Brasil

\footnotetext{
${ }^{1}$ Professor adjunto do Departamento de Geografia do Instituto de Geociências da UFMG
} 


\section{1 - INTRODUÇÃO E OBJETIVOS}

Apesar do intenso esforço dos demógrafos no Brasil no sentido de elaborar estatísticas mais acuradas que descrevam o processo migratório; a utilização destes dados tem se mostrado restrita. A carência desses estudos reside principalmente na dificuldade de manipulação dos quesitos sobre o local de residência anterior dos indivíduos residentes nos domićlíos recenseados. No caso da migração de data-fixa, como o próprio termo sugere, esse local possui uma data específica no passado, ou seja, cinco anos antes da data de referência da pesquisa. $O$ problema surge quando os respondentes não sabem ou não se lembram desse local.

No que tange aos Censos Demográficos brasileiros, verifica-se que uma crescente atenção tem sido dada à mensuração dos fluxos migratórios(CARVALHO, 1985). Nos censos de 1960 e de 1970 as questões sobre migração foram direcionadas apenas aos não-naturais dos municípios e estes quesitos dizem respeito ao tempo de residência sem interrupção na UF e no município, lugar de procedência (UF ou país estrangeiro) e situação do domicílio (urbano ou rural). No Censo de 1980 houve avanços importantes. A pesquisa não se limitou aos não-naturais e, além das migrações intermunicipais, perguntou-se também sobre as intramunicipais, porém sem indagar sobre o tempo em que se deu o evento. Uma novidade relevante foi a indicação do nome do município de residência anterior, por parte daqueles com menos de dez anos de residência no município (CARVALHO; RIGOTTI, 1998).

O Censo de 1991, é o mais completo no que diz respeito aos dados sobre migração, o que amplia as possibilidades de pesquisa nesse campo. A grande inovação encontra-se na informação de "data fixa", obtida por meio do quesito que Indique a sigla da UF e o nome do município ou país em que residia em 01/09/1986". Sem prejuízo para os dados relacionados à migração de última etapa, emigrantes e imigrantes identificados a partir desse quesito guardam semelhança conceitual com os imigrantes e emigrantes implícitos no saldo migratório resultante de técnica indireta (CARVALHO; MACHADO, 1992).

De um modo geral, desde 1991, o Censo vem seguindo uma lógica de arguição na captação desta informação:o primeiro quesito indaga se o local de nascimento dos residentes é o município de residência atual; se a resposta for "não" ou "sim, mas já morou em outro", o indivíduo é considerado um "migrante". Para esses, indaga-se sobre o tempo ininterrupto 
de residência naUF e município atuais e o, mais importante para efeito deste artigo, o local de residência exatos cinco anos antesda data de referência da pesquisa. São três os tipos de respostas possíveis: "um local específico", "local ignorado" e, para os menores de cinco anos, "não era nascido".

No intuito de facilitar o manuseio dos microdados, a partir do Censo de 2000, foi introduzido um quesito especifico para a seleção dos registros de migrantes de data-fixa. No Censo de 2000, o rótulo do quesito foi"residência em 31 de julho de 1995" e no de 2010, "residência em 31 de julho de 2005". A introdução desses quesitos na base dos microdados trouxe, por um lado,alguma facilidade na seleção desses registros. Por outro lado, gerou questões que ainda não foram devidamente debatidas, pois, como se procurou demonstrar nesse artigo, há certas sérias inconsistências na adoção desse procedimento.

O objetivo principal deste artigo é tecer, portanto, uma discussão crítica da mensuração da migração municipal de data-fixa, apontando as dificuldades e inconsistências presentes no manuseio do microdados dos Censos Demográficos de 1991, 2000 e 2010.Como objetivos específicos, pretende-se fornecer estimavas de imigrantes e emigrantes, provenientes dos três Censos, com base na seleção de registros por meio do controle da idade e tempo de residência municipal, alémdo tratamento aos casos cuja localidade foi omitida ou ignorada.

\section{2 - METODOLOGIA}

Tal como já explicitado, há dois componentes presentes na migração de data-fixa que devem ser observados para a seleção dos registros desses migrantes: a idade dos respondentes e o tempo de residência municipal. Com a introdução das variáveis de seleção desses registros, pouca atenção foi dada esses elementos e foram tomadas como corretas as estimativas geradas por meio deles. A hipótese deste trabalho é a de que esses quesitos não devem deixar de fora registros cujotempo de residência no município seja inferior a cinco anos, bem como devem excluir os migrantes que não eram nascidos na data de referência, ou seja, os menores de cinco anos de idade.

As estimativas dos migrantes municipais de data-fixa dos Censos Demográficos são gerados com base em dois critérios distintos de seleção dos registros: o primeiro, no qual se controla a idade (maior ou igual a cinco anos) o tempo de residência no município atual 
(menor que cinco anos), e o município de residência cinco anos antes da data de referência do censo; e o segundo, com base nos quesitos fornecidos pelo IBGE, encontrados diretamente nos microdados.

Os quesitos de migração de data-fixa dos microdados de 1991 são os mais trabalhosos de serem manuseados, uma vez que não há uma variável derivada para a seleção desses registros e, para dificultar, a variável indicadora do município de residência cinco anos antes da data de referência do Censo não possui o código completo do município, necessitando assim que o código da UF correspondente seja agregado aos seus valores para que ela possa fazer sentido. Esses códigos constam do quesito "UF de residência há cinco anos atrás", vale ressaltar, ainda, que essa variável apresenta o código 70, que indica que o município de residência há exatos cinco anos da data de referência da pesquisa foi o mesmo município de residência atual. Dessa forma, para selecionar os registros de data-fixa, tem-se que adotar os seguintes critérios: tempo de residência municipal menor que cinco anos e UF de residência na data-fixa diferente de 70. Com a introdução do quesito "residência em 31 de julho de 1995", nos microdados do Censo de 2000, basta selecionaros seguintes códigos dessa variável: 3, 4 e 5 (respectivamente: em outro município, na zona urbana; em outro município, na zona rural; em outro país). No censo de 2010, infelizmente, não basta que se selecione os códigos 1 (UF ou município) e 2 (país estrangeiro) da variável "residência em 31 de julho de 2005", tal como o indicado no Censo anterior. Ocorre que o código 1 dessa variável incorpora registros cujo tempo de residência é de cinco anos, bem como registros cuja municipalidade na data-fixa é a mesma de residência atual.Esses casos, obviamente, devem ser excluídos.

Outro elemento de incerteza na geração dessas estimativas diz respeito à origem desses fluxos. Como oscensos captam as informações no local de moradia dos migrantes, o destino final do processo migratório é dado.O mesmo não ocorre, contudo,em relação à sua origem. Nos casos em que essa informação encontra-se omitida ou ignorada, os resultados devem ser redistribuídos de acordo a proporção dos resultados cuja origem é conhecida. Esse procedimento também requer certa dose de cuidado. 


\section{3 - RESULTADOS}

A Tabela 1 traz os resultados das estimativas dos migrantes intermunicipais de data-fixa dos Censos Demográficos gerados com base em dois critérios distintos de seleção dos registros: o primeiro, no qual se controla a idade (maior ou igual a cinco anos) o tempo de residência no município atual (menor que cinco anos), e o município de residência 'há exatos cinco anos' diferente do município de residência atual; e o segundo, com base nos quesitos fornecidos pelo IBGE, encontrados diretamente nos microdados. A diferença observada nas estimativas referentes a 1991 se devem a 181 pessoas que foram classificadas como migrantes de data-fixa, porém seu município de residência atual era o mesmo do de cinco anos atrás, 145 em Marabá-PA e 36 em Posse-GO. O mesmo ocorre em 2000, só que em Brasília, com 148 pessoas. Já a diferença encontrada nos resultados de 2010 se deve ao que já foi mencionado anteriormente: o quesito "residência em 31 de julho de 2005" não exclui os casos em que o município de residência atual é o mesmo do de "data-fixa" e, inexplicavelmente, incorpora os casos cujo tempo de residência é igual a 5 anos ininterruptos.

Tabela 1

Brasil:1991/2010. Estimativas dos migrantes de data-fixasegundo diferentescritérios de seleção dos registros.

\begin{tabular}{|c|c|c|c|}
\hline Seleção dos registros & Total & Origem desconhecida & $\%$ \\
\hline \multicolumn{4}{|l|}{1991} \\
\hline Idade, tempo e local de residência atual e há cinco anos & 13982769 & 461027 & 3,3 \\
\hline IBGE - local de residência há cinco anos & 13982950 & 461027 & 3,3 \\
\hline Variação Percentual & 0,00 & 0,00 & 0,00 \\
\hline \multicolumn{4}{|l|}{2000} \\
\hline Idade, tempo e local de residência atual e há cinco anos & 15458738 & 744673 & 4,82 \\
\hline IBGE - quesito direto & 15458886 & 744673 & 4,82 \\
\hline Variação Percentual & 0,00 & 0,00 & 0,00 \\
\hline \multicolumn{4}{|l|}{2010} \\
\hline Idade, tempo e local de residência atual e há cinco anos & 13892103 & 436378 & 3,14 \\
\hline IBGE - quesito direto & 18513450 & 964862 & 5,21 \\
\hline Variação Percentual & $-24,92$ & $-54,77$ & $-39,76$ \\
\hline
\end{tabular}

Fonte: IBGE. Censos Demográficos de 1991, 2000 e 2010 (microdados).

A Tabela 2 traz os resultados das estimativas dos migrantes intermunicipais e do saldo migratório de data-fixa das capitais das Unidades da Federação do país, mensurados com base nos microdados dos Censos Demográficos de 1991, 200 e 2010; já os mapas 1 a 12 explicitam a distribuição espacial dos movimentos populacionais de data fixa nos municípios brasileiros, a partir desses mesmos microdados - ou seja, são apresentados o mapeamento dos contingentes de emigrantes, imigrantes e o saldo migratório dessas localidades nos seguintes qüinqüênios: 1986/1991, 1995/2000 e 2005/2010. 
Tabela 2

Brasil: 1991/2010. Estimativas intermunicipais de data-fixa dos emigrantes, dos imigrantes, dos saldos migratórios e dos imigrantes internacionais das capitais das Unidades da

Federação

\begin{tabular}{|c|c|c|c|c|c|c|c|c|c|c|c|c|}
\hline \multirow{3}{*}{$\begin{array}{l}\text { Capitais das } \\
\text { Unidades } \\
\text { Federativas }\end{array}$} & \multicolumn{12}{|c|}{ Migrantes de data-fixa } \\
\hline & \multicolumn{4}{|c|}{ 2005-2010 } & \multicolumn{4}{|c|}{$1995-2000$} & \multicolumn{4}{|c|}{ 1986-1991 } \\
\hline & Emigrantes & Imigrantes & \begin{tabular}{c|c|} 
Saldo \\
migratório \\
intermunicipal
\end{tabular} & $\begin{array}{c}\text { Imigrantes } \\
\text { internacionais }\end{array}$ & Emigrantes & Imigrantes & \begin{tabular}{c|} 
Saldo \\
migratório \\
intermunicipal
\end{tabular} & $\begin{array}{c}\text { Imigrantes } \\
\text { internacionais }\end{array}$ & Emigrantes & Imigrantes & \begin{tabular}{|c|} 
Saldo \\
migratório \\
intermunicipal
\end{tabular} & $\begin{array}{c}\text { Imigrantes } \\
\text { internacionais }\end{array}$ \\
\hline Porto Velho & 23546 & 46897 & 23350 & 656 & 32724 & 31660 & -1065 & 300 & 27679 & 50821 & 23142 & 262 \\
\hline Rio Branco & 17741 & 17363 & -377 & 278 & 17551 & 20062 & 2510 & 149 & 12014 & 20101 & 8087 & 168 \\
\hline Manaus & 66920 & 95631 & 28710 & 1682 & 66930 & 112291 & 45361 & 1051 & 43483 & 78505 & 35022 & 333 \\
\hline Boa Vista & 17118 & 22968 & 5849 & 689 & 15143 & 37367 & 22224 & 847 & 6190 & 28882 & 22692 & 557 \\
\hline Belém & 119537 & 53331 & -66206 & 1376 & 143042 & 75527 & -67515 & 749 & 102025 & 87355 & -14669 & 525 \\
\hline Macapá & 18879 & 28235 & 9356 & 372 & 16133 & 33102 & 16968 & 304 & 9832 & 14822 & 4991 & 300 \\
\hline Palmas & 20146 & 48247 & 28101 & 406 & 15647 & 57106 & 41459 & 56 & 662 & 17255 & 16592 & \\
\hline São Luís & 77356 & 60156 & -17200 & 649 & 76802 & 72124 & -4678 & 52 & 61547 & 80358 & 18811 & 266 \\
\hline Teresina & 49498 & 44628 & -4870 & 223 & 52165 & 58239 & 6074 & 115 & 46841 & 65929 & 19088 & 184 \\
\hline Fortaleza & 142162 & 94918 & -47245 & 2522 & 151741 & 128685 & -23056 & 943 & 144246 & 144940 & 694 & 827 \\
\hline Natal & 78701 & 48047 & -30654 & 904 & 73750 & 61939 & -11811 & 479 & 52357 & 66111 & 13754 & 258 \\
\hline João Pessoa & 47780 & 49775 & 1996 & 1378 & 50658 & 54493 & 3835 & 366 & 40511 & 52038 & 11528 & 97 \\
\hline Recife & 137378 & 63690 & -73688 & 1956 & 159208 & 68816 & -90392 & 1204 & 181244 & 66527 & -114716 & 709 \\
\hline Maceió & 60305 & 44866 & -15440 & 402 & 55498 & 61874 & 6376 & 125 & 41074 & 67092 & 26018 & 304 \\
\hline Aracaju & 44931 & 42741 & -2190 & 304 & 58409 & 35705 & -22703 & 137 & 50306 & 43347 & -6959 & 38 \\
\hline Salvador & 162798 & 99578 & -63221 & 2976 & 155580 & 124787 & -30793 & 1388 & 123495 & 123523 & 28 & 1060 \\
\hline Belo Horizonte & 226596 & 116420 & -110176 & 5395 & 259806 & 142349 & -117457 & 2711 & 239343 & 135611 & -103732 & 2006 \\
\hline Vitória & 47969 & 30152 & -17817 & 981 & 53186 & 27688 & -25498 & 554 & 54589 & 28966 & -25623 & 322 \\
\hline Rio de Janeiro & 317075 & 182148 & -134928 & 12151 & 373470 & 225501 & -147969 & 9617 & 373416 & 166600 & -206816 & 6459 \\
\hline São Paulo & 796967 & 412800 & -384167 & 39174 & 1061530 & 533446 & -528083 & 18237 & 954723 & 559748 & -394975 & 13548 \\
\hline Curitiba & 168702 & 113472 & -55230 & 6695 & 176137 & 153561 & -22575 & 4605 & 135236 & 132361 & -2875 & 1683 \\
\hline Florianópolis & 50931 & 58398 & 7467 & 2652 & 38938 & 50715 & 11777 & 1663 & 28081 & 30292 & 2211 & 693 \\
\hline Porto Alegre & 121507 & 75552 & -45955 & 3014 & 131267 & 88643 & -42624 & 2273 & 139676 & 78415 & -61261 & 1810 \\
\hline Campo Grande & 50762 & 59802 & 9040 & 2575 & 52951 & 71723 & 18772 & 1260 & \begin{tabular}{|l|}
37720 \\
\end{tabular} & 78771 & 41051 & 485 \\
\hline Cuiabá & 52502 & 31720 & -20782 & 426 & 62922 & 45493 & -17429 & 301 & 41501 & 55535 & 14034 & 154 \\
\hline Goiânia & 139155 & 115218 & -23937 & 5538 & 153109 & 132080 & -21029 & 1253 & 128138 & 106685 & -21453 & 448 \\
\hline Brasília & 179898 & 190761 & 10862 & 6455 & 153109 & 189668 & 216864 & 3768 & 143750 & 195312 & 51562 & 2898 \\
\hline
\end{tabular}

Fonte: IBGE. Censos Demográficos de 1991, 2000 e 2010 (microdados). 


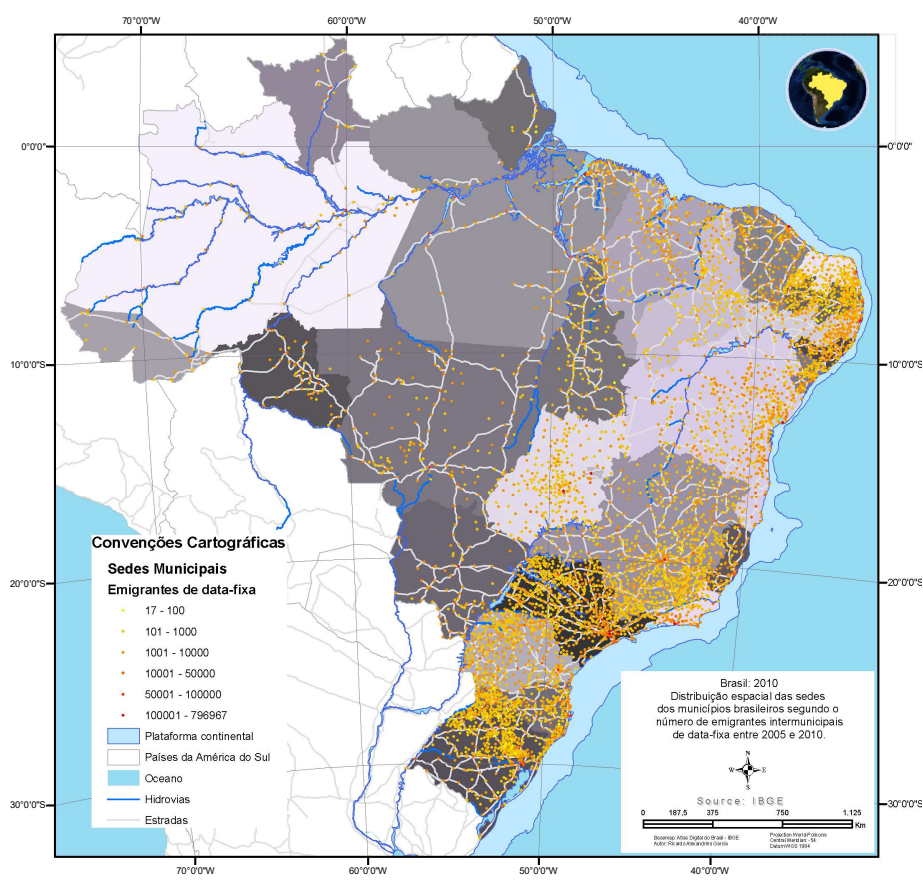

Mapa 1. Brasil: 2010. Distribuição espacial das sedes dos municipios brasileiros segundo o numero de emigrantes intermunicipais de data-fixa entre 2005 e 2010. Fonte: IBGE. Censo Demográfico de 2010 (microdados).

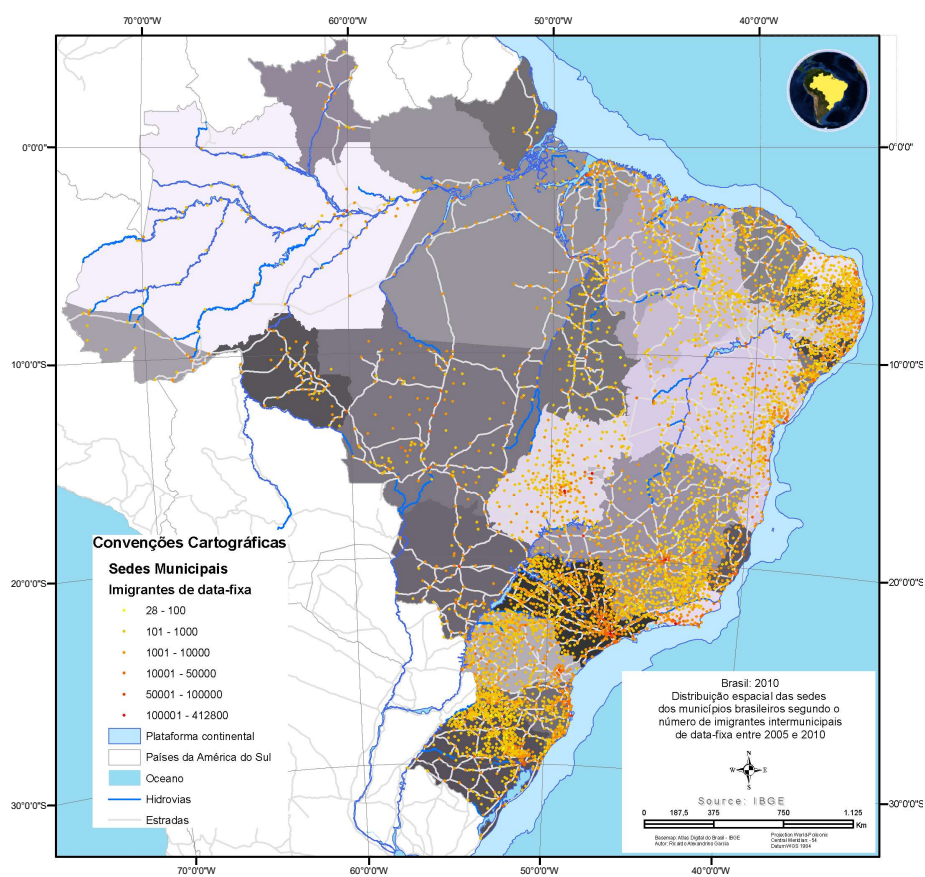

Mapa 2. Brasil: 2010. Distribuição espacial das sedes dos municípios brasileiros segundo o número de imigrantes intermunicipais de data-fixa entre 2005 e 2010. Fonte: IBGE. Censo Demográfico de 2010 (microdados).

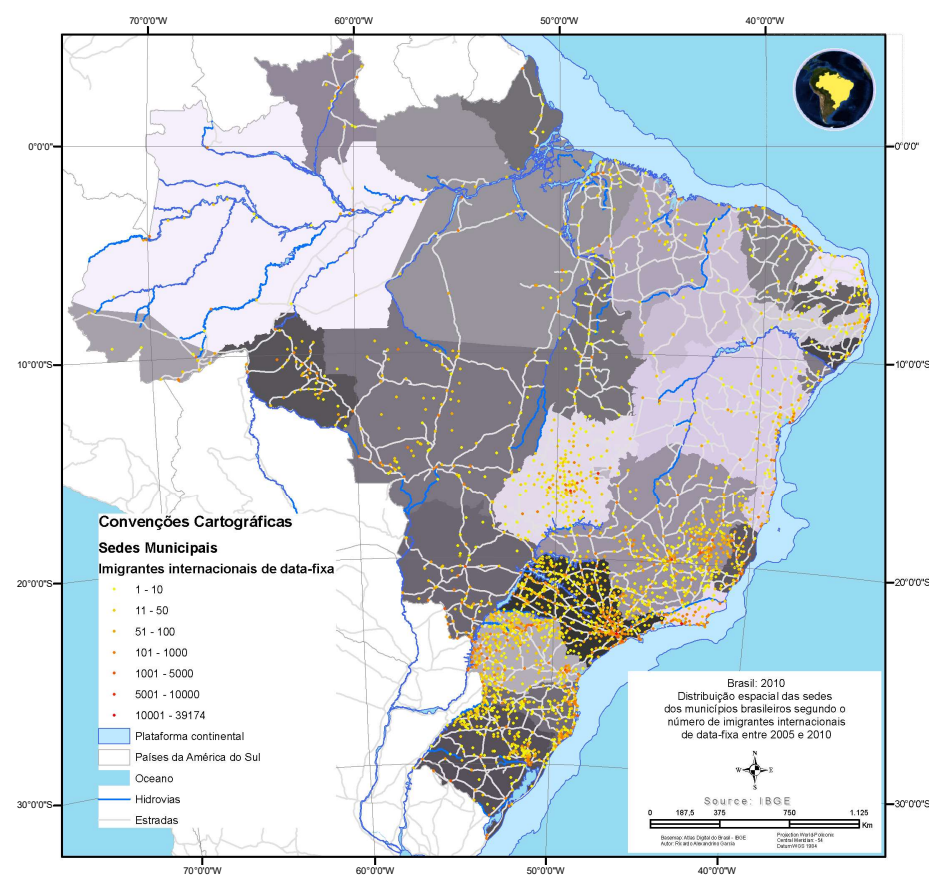

Mapa 3. Brasil: 2010. Distribuição espacial das sedes dos municipios brasileiros segundo o número de imigrantes internacionais de data-fixa entre 2005 e 2010. Fonte: IBGE. Censo Demográfico de 2010 (microdados).

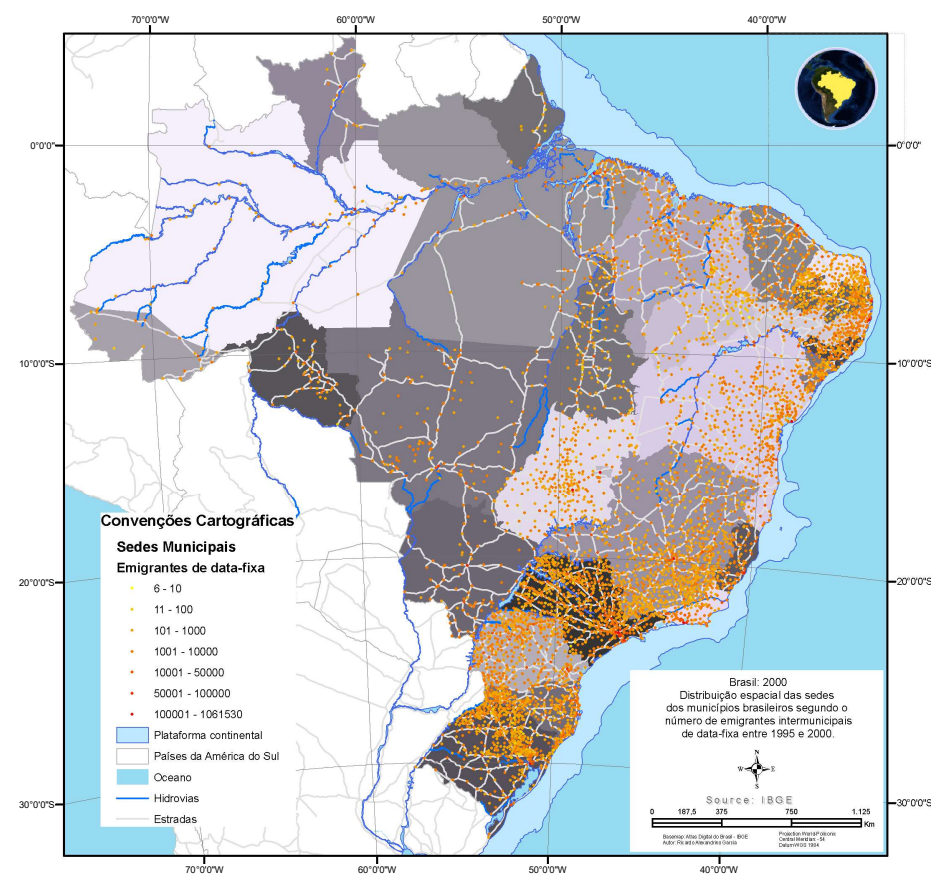

Mapa 4. Brasil: 2000. Distribuição espacial das sedes dos municípios brasileiros segundo o numero de emigrantes intermunicipais de data-fixa entre 1995 e 2000. Fonte: IBGE. Censo Demográfico de 2000 (microdados). 


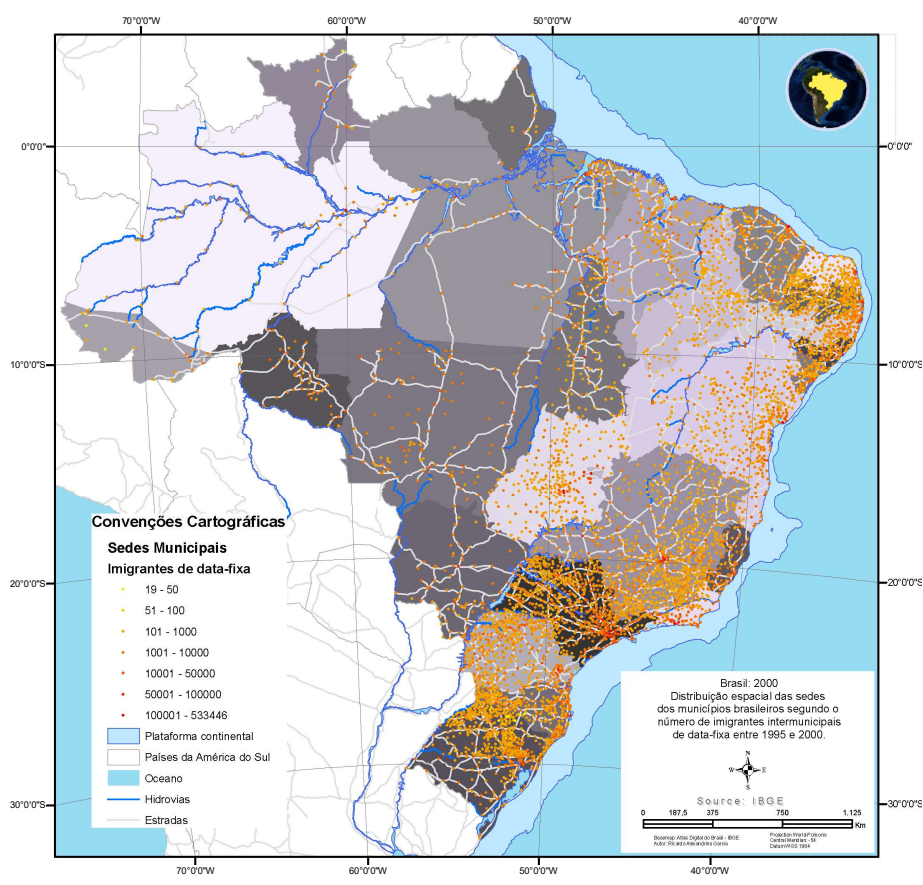

Mapa 5. Brasil: 2000. Distribuição espacial das sedes dos municipios brasileiros segundo o número de imigrantes intermunicipais de data-fixa entre 1995 e 2000. Fonte: IBGE. Censo Demográfico de 2000 (microdados).

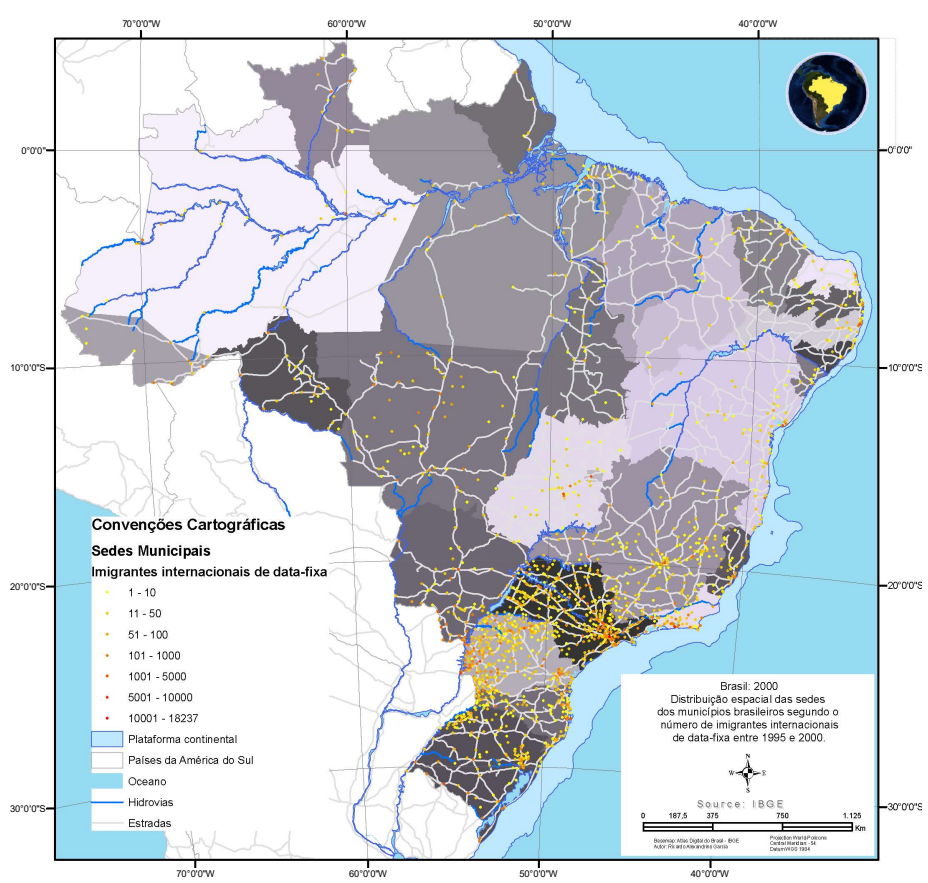

Mapa 6. Brasil: 2000. Distribuição espacial das sedes dos municipios brasileiros segundo o número de imigrantes internacionais de data-fixa entre 1995 e 2000. Fonte: IBGE. Censo Demográfico de 2000 (microdados).

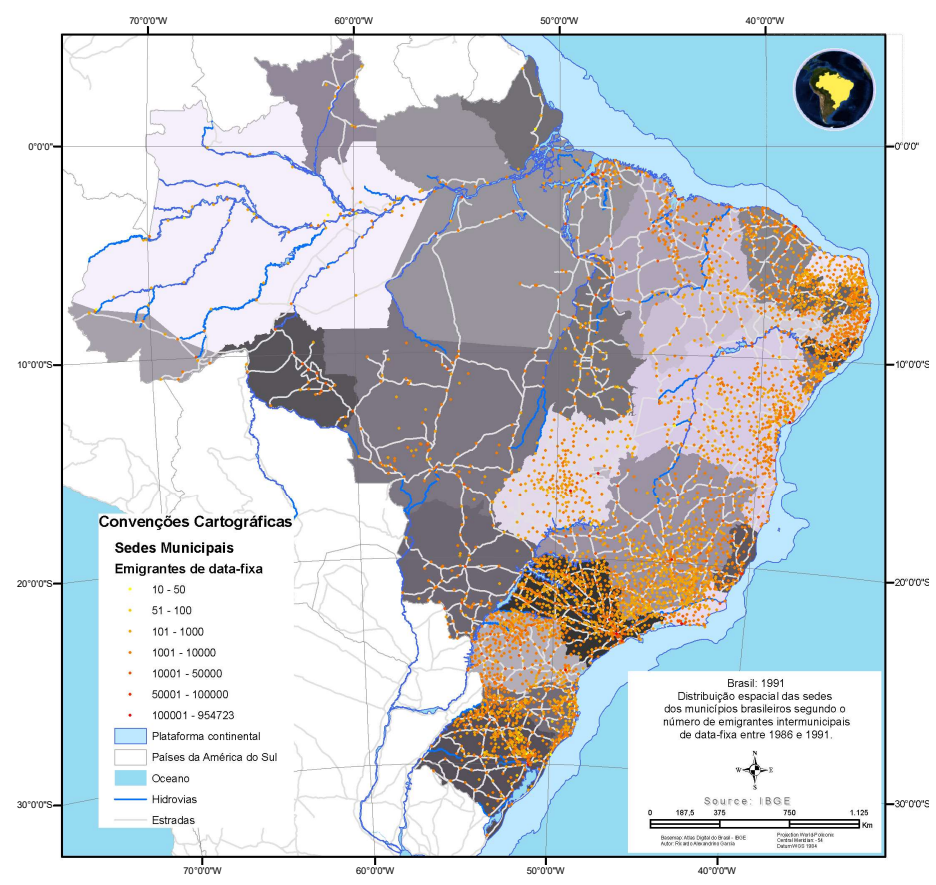

Mapa 7. Brasil: 1991. Distribuição espacial das sedes dos municipios brasileiros segundo o numero de emigrantes intermunicipais de data-fixa entre 1986 e 1991. Fonte: IBGE. Censo Demográfico de 1991 (microdados).

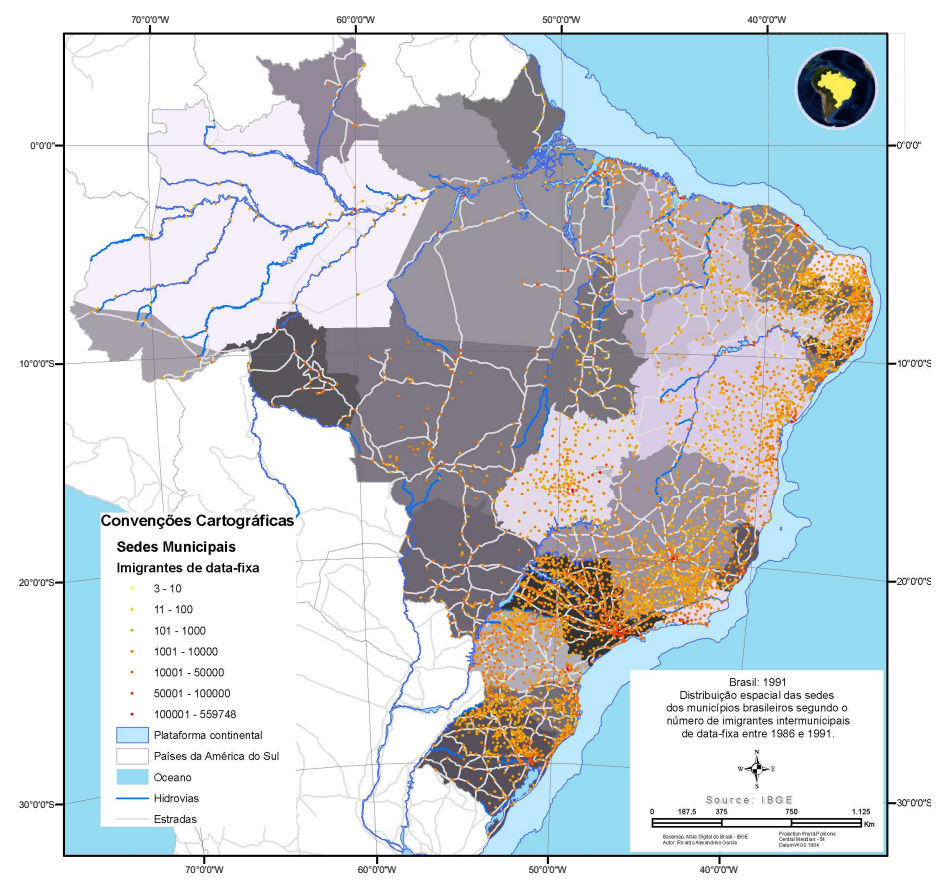

Mapa 8. Brasil: 1991. Distribuição espacial das sedes dos municípios brasileiros segundo o número de imigrantes intermunicipais de data-fixa entre 1986 e 1991. Fonte: IBGE. Censo Demográfico de 1991 (microdados). 


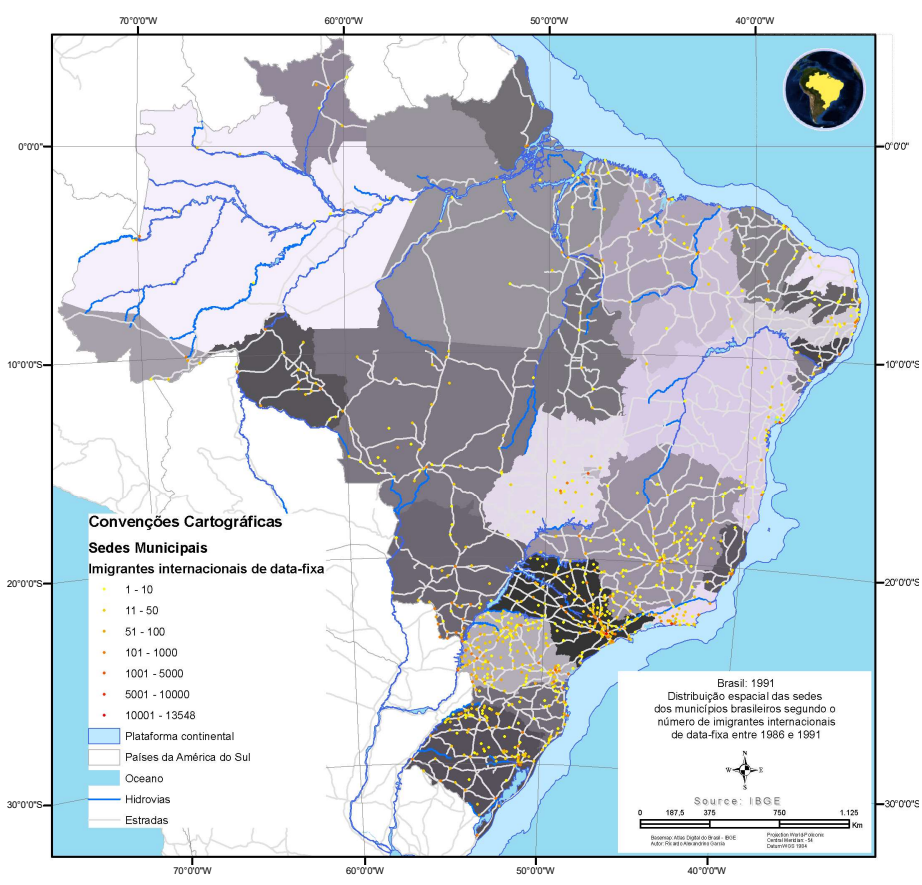

Mapa 9. Brasil: 1991. Distribuição espacial das sedes dos municipios brasileiros segundo o número de imigrantes internacionais de data-fixa entre 1986 e 1991. Fonte: IBGE. Censo Demográfico de 1991 (microdados).

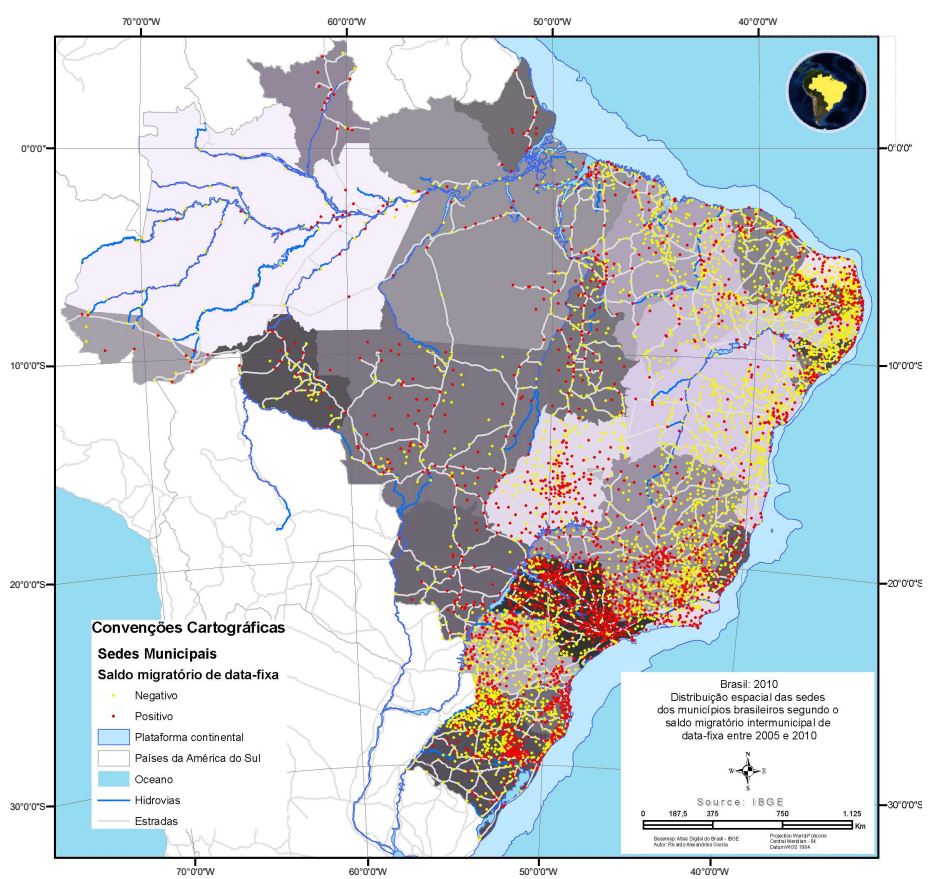

Mapa 10. Brasil: 2010. Distribuição espacial das sedes dos municipios brasileiros segundo o saldo migratório intermunicipal de data-fixa entre 2005 e 2010. Fonte: IBGE. Censo Demográfico de 2010 (microdados).

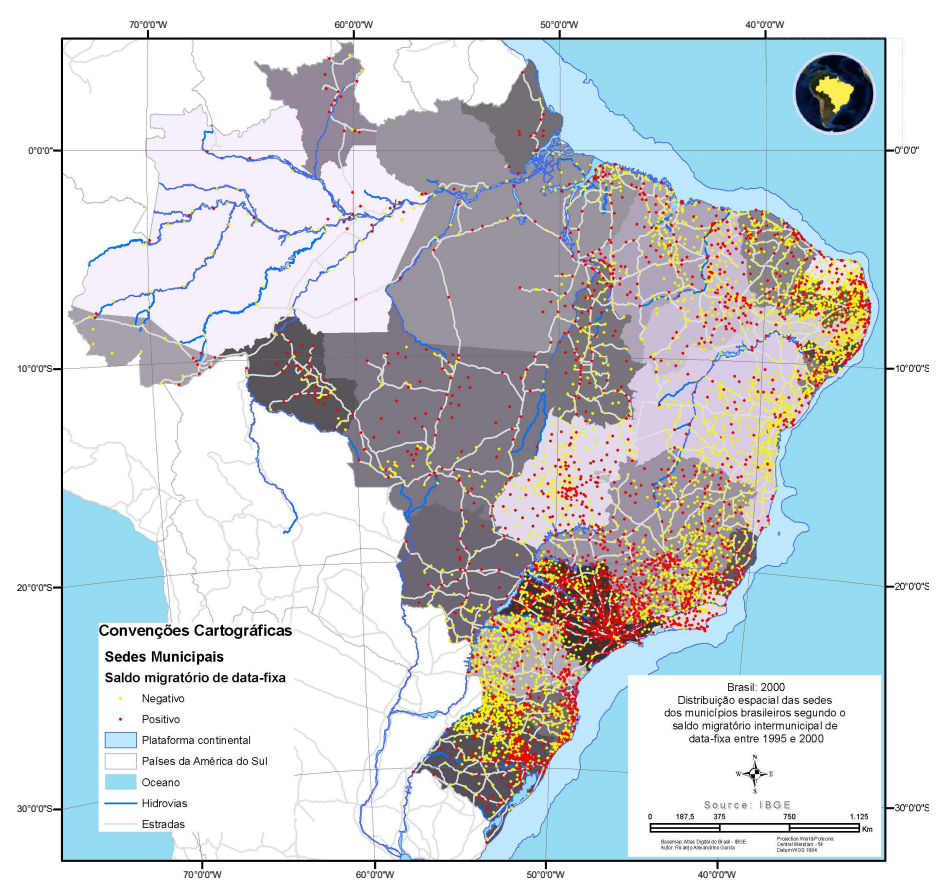

Mapa 11. Brasil: 2000. Distribuição espacial das sedes dos municipios brasileiros segundo o saldo migratório intermunicipal de data-fixa entre 1995 e 2000. Fonte: IBGE. Censo Demográfico de 2000 (microdados).

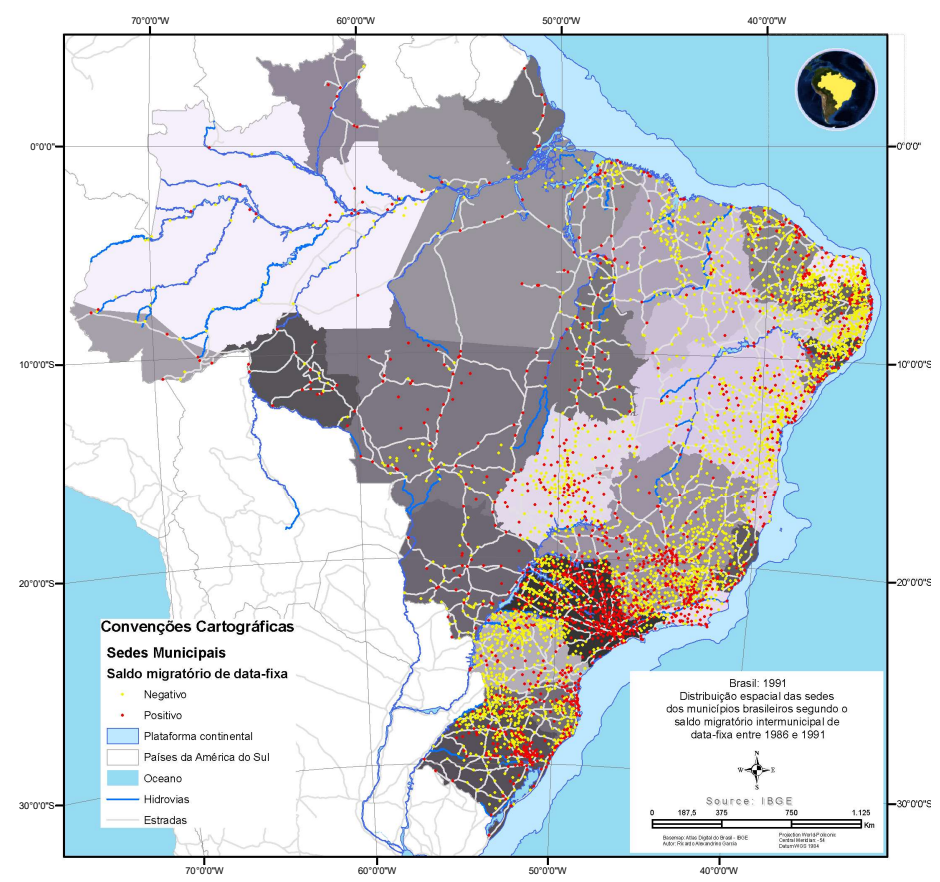

Mapa 12. Brasil: 1991. Distribuição espacial das sedes dos municípios brasileiros segundo o saldo migratório intermunicipal de data-fixa entre 1986 e 1991. Fonte: IBGE. Censo Demográfico de 1991 (microdados). 


\section{4 - CONSIDERAÇÕES FINAIS}

Os microdados da amostra dos Censos Demográficos constituem-se na melhor base de dados para o estudo da migração no Brasil, contudo, é necessário muita cautela no seu manuseio, nesse sentido, é melhor pecar por excesso do que por falta de zelo nos critérios de seleção dos registros. Ao que tudo indica, o procedimento de seleção que combina a idade, o tempo de residência no município atual e o município de residência cinco anos antes da data de referência do Censo parece ser o mais adequado para a elaboração de estimativas do número de migrantes de data-fixa.

Já o "prorrateamento" adequado dos resultados cuja localidade de origem é ignorada levando-se em conta quando possível as informações sobre a UF de residência na data fixa - é fundamental para que seja quantificada a emigração quinquenal dos municípios brasileiros e, com isso, saldos e taxas líquidas de migração. Sempre vale lembrar que o saldo migratório proveniente da informação de data-fixa é, em detrimento da informação da migração de ultima etapa, o que mais se aproxima do verdadeiro conceito de saldo migratório.

Os dados de migração de data-fixa no Censo Demográfico de 2010, no entanto, revelam-se problemáticos e devem ser analisados com grande cautela, pois não há evidências de que estes movimentos populacionais intermunicipais tenham regredido aos níveis da década de noventa do século passado. Se isso realmente vem ocorrendo no país, talvez essa tendência seja somente corroborada no Censo Demográfico de 2020.

\section{REFERÊNCIAS BIBLIOGRÁFICAS}

Carvalho, J. A M. Estimativas Indiretas e Dados sobre Migrações: uma avaliação conceitual e metodológica das informações censitárias recentes, Revista Brasileira de Estudos Populacionais, vol. 2, n. 1, p. 31-73, 1985.

Carvalho, J. A M.; Machado, C. Quesitos sobre Migrações no Censo Demográfico de 1991, Revista Brasileira de Estudos de População, vol. 9, n. 1, p. 22-34, 1992.

CARVALHO, J. A. M.; RIGOTTI, J. I. R. Os dados censitários brasileiros sobre migrações internas: algumas sugestões para análise. Revista Brasileira de Estudos de População. Brasília: ABEP, v. 15, n. 2, p. 7-17, jul./dez. 1998. 